\title{
Sachse Laser in post-trauma urethral stricture: a valid alternative before Urethroplasty.
}

\author{
Astrit Mustafaj ${ }^{1,3 *}$, Evisa Zhapa ${ }^{1}$, Francesco Saverio Grossi ${ }^{1,2}$
}

Received: 24 March 2018; Accepted: 30 June 2018; Published online: 20 July 2018: DOI: https://doi.org/10.32391/ajtes.v2i2.8

\begin{abstract} efficacy of the Internal Urethrotomy with Holmium Laser (Sachse laser). Volume 363 cc.No patients relapsed during follow-up time from 3 to 24 months.

Keywords: Treatment modality, urethral strictures, alternative method

${ }^{*}$ Corresponding Author: Astrit Mustafa MD

$\equiv$ Email. astritmustafaj@yahoo.com

${ }^{1}$ Urology Departament, Italo-Albanian, "Salus" Hospital

${ }^{2}$ Complex Structure of Urology, Hospital SS Annunziata of Taranto.

${ }^{3}$ University Hospital of Trauma Tirana, Albania
\end{abstract}

Introduction: The most commonly used treatment modality for urethral strictures is the direct visual internal urethrotomy method according Sachse cold knife, but with low long-term success rate. Alternative method after failure is isurethroplasty with preputial flap or Buccal mucosa. The aim of this presentation is to report the

Material and methods: We report three cases of urethral stenosis after trauma which treated with Internal Urethrotomy with Holmium Laser (Sachse laser) after failure of multiple treatments with Sachse cold knife. We evaluated and compared the uroflowmetry parameters before and after Sachse laser.

Results: The average of uroflowmetry parameters before incision were: $Q$ max $4.5 \mathrm{ml} / \mathrm{sec}, Q$ med $3 \mathrm{ml} / \mathrm{sec}$. Voided Volume $323 \mathrm{cc}$, while after incision with Sachse laser were: Q max $30 \mathrm{ml} / \mathrm{sec}$, Q med $12 \mathrm{ml} / \mathrm{sec}$. Voided

Conclusion: Even though these are only a few cases, we think that Sachse laser is a valid alternative after unsuccessful Sachse cold knife and before Urethroplasty, even in patients with urethral stricture after trauma. 


\section{Introduction}

Urethral stricture is one of the most difficult urological problems to cure adequately and is known to mankind since ages as it has been documented in ancient literature of the Hindus,[1] Egyptians and Greeks.[2] Minimally invasive surgical approaches are utilized efficiently and safely in the treatment of various disorders in urological practice. However, treatment options for urethral strictures have been limited both in number and level of success, as judged by the high recurrence rates. Treatment options for urethral strictures include self-catheterization, bougie dilation, balloon dilation, cold-knife optical internal urethrotomy (OIU), laser urethrotomy methods and open reconstructive urethroplasty, which is generally reserved for cases which did not benefit from endoscopic approaches [2]. OIU, described by Sachse in 1974, is still the preferred method due to the practical and minimally invasive nature of the procedure [3]. One of the alternative approaches is the correction of the stricture using laser energy, which was first used in urology in 1984 and established as a common method in internal urethrotomy since the nineties [4].

The aim of this retrospective study is to report our experience with the treatment by Holmium Laser Internal Urethrotomy (HIU) of three cases of urethral stricture after trauma multi treated before by cold-knife optical internal urethrotomy (OIU), and compare the pre- and post- operative uroflowmetry results.

\section{Materials and Methods}

This is a retrospective study of 3 patientswhopresentedto our Clinic for urethral stricture disease after trauma multi treated before by cold-knife optical internal urethrotomy (OIU), between 2013 - 2016.

We extracted data from medical records and our Medarchiver system on uroflowmetry and cystoscopyfindings, including the site and length of stricture, number of previous urethrotomies or other surgeries for the treatment of urethral stenosis.

All patients with symptoms or signs suggestive of urethral stricture underwent auroflowmetry (UFM) and cystourethroscopyto confirm the diagnosis and determine urethral stricture length.

One urologist performed the urethrotomies using a single incision at the 12 o'clock position or using a modified procedure including multiple radial incisions at the 3,9 , and 12 o'clock positions; the incisions were made with a cold knife and laser.

Follow-up data included subjective and objective results as Uroflowmetry parametersand whether subsequent intervention was needed. All patients underwent a uroflowmetry after 3,6 , and 12 months from surgery.

Symptoms of recurrence included decreased force of the urine stream, feelings of incomplete bladder emptying, or recurrent urinary tract infections. Signs of recurrence were a significant increase in postvoid residual urine on bladder ultrasound or bladder scan, decreased urine flow rate ( $<15 \mathrm{~mL} /$ second), or stricture as determined by diagnostic cystoscopy or retrograde urethrogram. Absence of symptoms or signs of recurrent stricture in any patient at last follow-up defined the success of the procedure. The end point of the follow-up was the last visit that showed failure of treatment or being recurrence-free for minimum 24 months.

\section{Results and Discussion}


The mean age was 48 years (range: $44-53$ ). Three male patients with urethral stricture disease after trauma were treated from 2013-2016.

Patient 1: 53 years old, after a car incident and urethral rupture he had a termino-terminal anastomosis of the bulbar urethra. For urethral stenosis after surgery, he underwent a Cold knife sachse incision in another hospital which failed and 6 months after it presented at our hospital in urinary retention.

We decided to do a Holmium Laser Internal Urethrotomy (HIU).

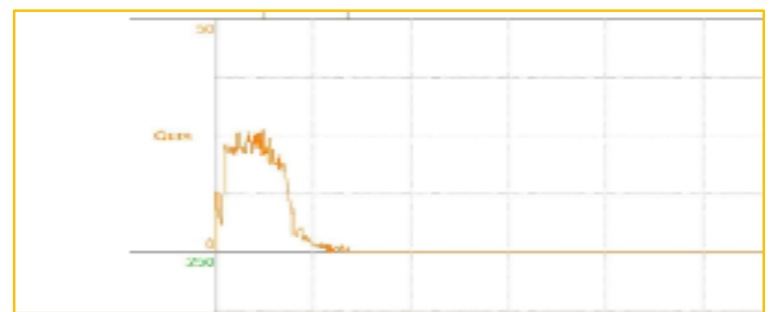

UFM after 1 month from the Incision: Q max 24 $\mathrm{ml} / \mathrm{sec}, Q$ med $13 \mathrm{ml} / \mathrm{sec}$. Voided Volume175 c

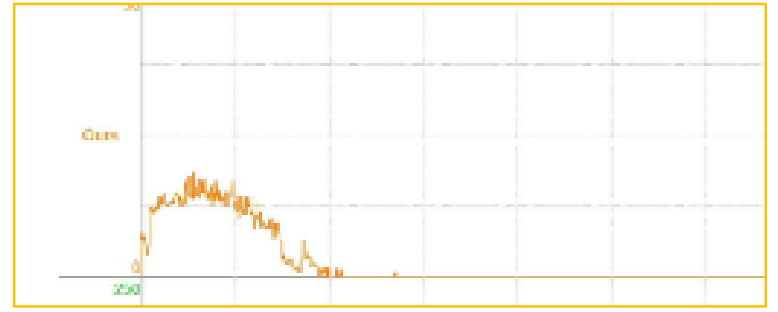

UFM after 6 months from the Incision: Q max 14 $\mathrm{ml} / \mathrm{sec}, \mathrm{Q}$ med $9 \mathrm{ml} / \mathrm{sec}$. Voided Volume $180 \mathrm{c}$

Patient 2: 44 years old, after a car incident and bulbar urethral stenosis he had 3 cold-knife optical internal urethrotomy (OIU) in three different European Centers (Spain, Italy, France) from September 2014 to September 2015. He presented to us with LUTS, sensation of non-emptying his bladder after micturition, reduction of the urinary stream. We performed a uroflowmetry and this is the result before surgery.

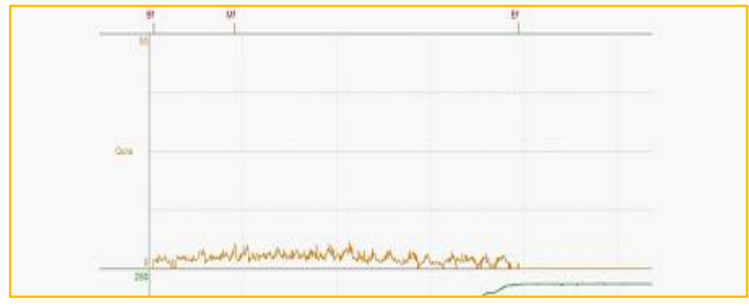

UFM before Incision Q max $2 \mathrm{ml} / \mathrm{sec}, Q$ med 1 $\mathrm{ml} / \mathrm{sec}$. Voided Vol $233 \mathrm{cc}$.

After a Holmium Laser Internal Urethrotomy (HIU) of a pre sfinteric annular stenosis of $3 \mathrm{~mm}$ long this is the result of the uroflowmetry.

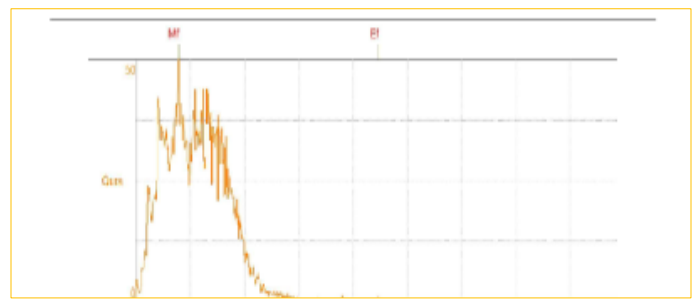

UFM after 3 months from the Incision: Q max 38 $\mathrm{ml} / \mathrm{sec}$, Q med $19 \mathrm{ml} / \mathrm{sec}$. Voided Vol $550 \mathrm{cc}$.

We don't have any other information of thi;s patient after three months.

Patient 3: 48 years old, 5 years before he underwent different urethral dilatation for urethral stenosis. He presented to us with LUTS, sensation of non-emptying his bladder after micturition, reduction of the urinary stream. We performed a uroflowmetry and this is the result before surgery. 


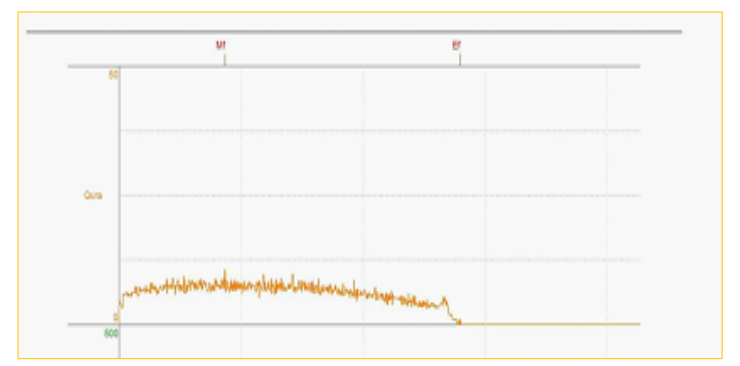

UFM before Incision Q max $7 \mathrm{ml} / \mathrm{sec}, Q$ med 5 $\mathrm{ml} / \mathrm{sec}$. Voided Vol $422 \mathrm{cc}$.

Theurethrocystoscopy evidenced multiple stenosis of the penile urethra from two $\mathrm{cm}$ from the external meatus until the internal sphincter where we performed a Holmium Laser Internal Urethrotomy (HIU). These are the results of uroflowmetry after the surgery.

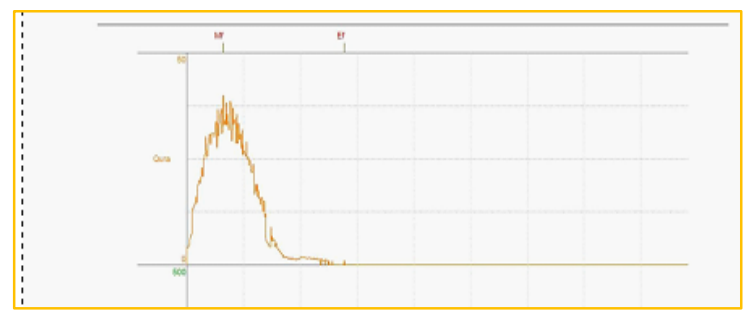

UFM after 1 month from the removal of the catheter: $Q$ max $35 \mathrm{ml} / \mathrm{sec}, Q$ med $13 \mathrm{ml} / \mathrm{sec}$. Voided Volume $311 \mathrm{cc}$

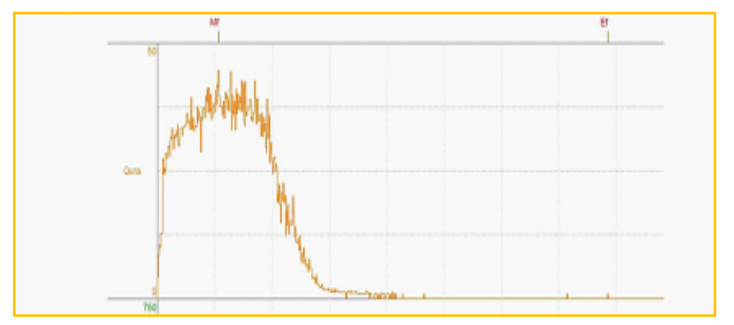

UFM after 1 year from the Incision: Q max 40 $\mathrm{ml} / \mathrm{sec}, Q$ med $17 \mathrm{ml} / \mathrm{sec}$. Voided Vol $600 \mathrm{cc}$

In our results the average of uroflowmetry parameters before incision were: $\mathrm{Q} \max 4.5 \mathrm{ml} / \mathrm{sec}$,
Q med $3 \mathrm{ml} / \mathrm{sec}$. Voided Volume $323 \mathrm{cc}$, while after incision with Sachse laser were: Q $\max 30 \mathrm{ml} / \mathrm{sec}, \mathrm{Q}$ med $12 \mathrm{ml} / \mathrm{sec}$. Voided Volume $363 \mathrm{cc}$. No patients relapsed during follow-up time from 3 to 24 months.

Urethral strictures are often treated withurethrotomy, most commonly direct visual internal urethrotomy [5]. With the introduction of lasers, holmium laserurethrotomy was subsequently used in many centers withequal recurrence outcomes as achieved with VIU $[6,7,10$, $11]$.

Many urologists prefer VIU over urethral reconstructionbecause of its ease to perform, low cost, short hospital stay, and perceived low complication rate. They may opt to repeatVIU several times to avoid complex urethral reconstruction, which requires significant surgical experience. This trend continues despite the moderate success rate reported inthe selected patients.

Several studies have examined the costeffectiveness ofmanaging anterior urethral strictures. Urethroplasty as theprimary therapy was cost-effective only when the expectedsuccess rate of the first VIU was less than 35\% [8], whereasVIU became more favorable when the long-term risk of stricture recurrence was less than $60 \%$ [9]. If a repeaturethrotomy is required, open urethroplasty is the treatmentof choice for recurrent urethral stricture

\section{Conclusions}

Both, cold knife and holmium laser, have been effective in providing immediate relief to patients with urethral strictures. Holmium laser is technically more demanding than cold knife for internal urethrotomy. The complications of both modalities 
are low and easily manageable. Lack of a significant

difference between recurrence rates and complication rates of HIU and OIU suggests that both are safe and effective treatment methods in urethral strictures.

Even though we report only a few cases, we think that Sachse laser is a valid alternative after unsuccessful Sachse cold knife and before Urethroplasty, even in patients with urethral stricture after trauma. Larger studies encompassing cases with different characteristics may help to identify the variables that may favor or discourage the use of either method in future studies

\section{References}

1. Das S. Urology in ancient India. Indian J Urol 2007; 23: 2-5.

2. Heyns CF, van der Merwe J, Basson J, van der Merwe A. Treatment of male urethral stricturespossible reasons for the use of repeated dilatation or internal urethrotomy rather than urethroplasty. S Afr J Surg. 2012; 50: 82-87.

3. Sachse H. Treatment of urethral stricture: transurethral slit in view using sharp section. Fortschr Page Med. 1974; 92: 12-15.

4. Dutkiewicz SA, Wroblewski M. Comparison of treatment results between holmium laser endourethrotomy and optical internal urethrotomy for urethral stricture. IntUrolNephrol. 2012; 44:

717-724.

5. T. J. Greenwell, C. Castle, D. E. Andrich, J.

T.MacDonald, D. L. Nicol, and A. R. Mundy, "Repeat urethrotomy and dilation for the treatment of urethral stricture are neither clinically effective nor cost-effective," The Journal of Urology, vol. 172, no. 1, pp. 275-277, 2004.

6. S.Kamp, T. Knoll,M.M.Osman, K.U. K“ohrmann, M. S.Michel, and P.Alken, "Low-power holmium: YAGlaser urethrotomy for treatment of urethral strictures: functional outcome and quality of life," Journal of Endourology, vol. 20, no. 1, pp. 38-41, 2006. 7. S. A. Dutkiewicz and M. Wroblewski, "Comparison of treatment results between holmium laser endourethrotomy and optical internal urethrotomy for urethral stricture," InternationalUrology and Nephrology, vol. 44, no. 3, pp. 717-724, 2012.

8. J. L. Wright, H. Wessells, A. B. Nathens, and W. Hollingworth, "What is the most cost-effective treatment for 1 to 2-cmbulbar urethral strictures: societal approach using decision analysis," Urology, vol. 67, no. 5, pp. 889-893, 2006.

9. K. F. Rourke and G. H. Jordan, "Primary urethral reconstruction: the cost minimized approach to the bulbous urethral stricture," Journal of Urology, vol. 173, no. 4, pp. 1206-1210, 2005.

10. Jain SK, Kaza RC, Singh BK. Evaluation of holmium laser versus cold knife in optical internal urethrotomy for the management of short segment urethral stricture. Urol Ann. 2014; 6: 328-33.

11. Pfalzgraf $D$, HäckerA.Sachse internal urethrotomy: endoscopic treatment of urethral strictures. Urologe A. 2013; 52: 657-61. 